\section{Light Transmittance and Depth of Cure of a Bulk Fill Composite Based on the Exposure Reciprocity Law}

Mateus Garcia Rocha ${ }^{1}{ }^{\circ}$, Jean-François Roulet $^{1}{ }^{\circledR}$, Mario Alexandre Coelho Sinhoreti ${ }^{2}$, Américo Bortolazzo Correr $^{2}$ (D) Dayane Oliveira ${ }^{1}$ (D)
'Department of Restorative Dental Sciences, Operative Dentistry Division, College of Dentistry, University of Florida, Gainesville, FL, USA

${ }^{2}$ Department of Restorative Dentistry, Dental Materials Division, Piracicaba Dental School, UNICAMP - Universidade Estadual de Campinas, Piracicaba, SP, Brazil

Correspondence: Dayane Oliveira, DDS, MSc, PhD, 1395 Center Dr. Room D9-6,32610 Gainesville, FL, United States. Tel: +1-352-846-6909. e-mail: doliveira@dental.ufl.edu

Key Words: CQ, camphorquinone, TPO, mono-alkyl phosphine, degree of conversion.
The objective of this study was to evaluate the effect of the exposure reciprocity law of a multi-wave light-emitting diode (LED) on the light transmittance (LT), depth of cure (DOC) and degree of conversion in-depth (DC) of a bulk fill composite. A bulk fill composite (EvoCeram ${ }^{\circledast}$ bulk fill, Ivoclar Vivadent) was photoactivated using the multiwave LED (VALO ${ }^{\mathrm{TM}}$ Cordless, Ultradent). The LED was previously characterized using a spectrophotometer to standardize the time of exposure when using the Standard or Xtra-Power modes with the same radiant exposure of $20 \mathrm{~J} / \mathrm{cm}^{2}$. LT was evaluated through samples of the bulk fill composite every millimeter till $4 \mathrm{~mm}$ in-depth. DOC was evaluated according to the ISO 4049. DC of the central longitudinal cross-section from each sample of the DOC test was mapped using FT-NIR microscopy. Data were statistically analyzed according to the experimental design $(\alpha=0.05 ; \beta=0.2)$. The radiant exposure in the violet wavelength range for Standard and Xtra-Power was 4.5 and $5.0 \mathrm{~J} / \mathrm{cm}^{2}$, respectively; for the blue wavelength range the radiant exposure for Standard and Xtra-Power was 15.5 and $15.0 \mathrm{~J} / \mathrm{cm}^{2}$, respectively. There was no statistical difference in the DOC using Standard or Xtra-Power light-curing modes, but the DOC was lower than the claimed by the manufacturer $(4 \mathrm{~mm}$ ). The DC was not significantly affected by the light-curing mode up to $4 \mathrm{~mm}$ in depth ( $p>0.05$ ). According to exposure reciprocity law, the reduction in exposure time using the same radiant exposure did not affect the depth of cure of the bulk fill composite.

\section{Introduction}

High powered light-curing units (LCUs) have increased irradiance and claimed as it could be used for shorter exposure time, thus reducing the curing time needed for resin-based composites (RBCs) and the chairside procedure time (1-2). The increase on irradiance and reduction in light exposure time needed to ensure adequately cure of RBCs is based on the statement that the degree of conversion and mechanical properties of RBCs are dependent upon the radiant exposure $\left(\mathrm{J} / \mathrm{cm}^{2}\right)(3)$, which is the product of irradiance $\left(\mathrm{mW} / \mathrm{cm}^{2}\right)$ and exposure time (s) (4). This principle is known as the "exposure reciprocity law", and it has been an important topic for manufacturers that claim that similar properties can be achieved by RBCs using high power LCUs with a shorter exposure time that is compensated by high irradiance.

However, there are different assumptions in how the reciprocity law could affect RBCs physical-chemical properties, and previous studies highlighted the influence of composition and reactivity of the monomers used in RBCs on the outcome expected from the reciprocity law application. $(1-2,5)$ Besides that, there is a lack of information on spectral output distribution of LCUs, photoinitiators absorption, and how the same radiant exposure delivered in a different regiment of exposure time and irradiance can affect the properties of RBCs.

The recent improvement on the RBCs leads to the development of the bulk fill composites, which are indicated for direct restorations of posterior teeth using increments up to $4-5 \mathrm{~mm}$ in thickness (6). However, these bulk fill composites might contain different photoinitiators, and the efficiency of the photoinitiators is dependent upon their absorption characteristics and the compatibility with LCUs, which in the end, can affect the number of free radicals created $(6,7)$. As the degree of conversion is directly related to the efficiency of the photoinitiator system and the amount of light absorbed by the photoinitiator $(8,9)$, it should be expected that reciprocity should hold at a similar radiant exposure as the same total amount of efficient radicals is created by different irradiances and light exposure times.

However, such conclusions are unsatisfactory because they do not take into consideration that multi-wave LCUs will emit different wavelengths that have entirely different photon energies. Also, because the different wavelengths 
of light are generated at different points (in contrast to a QTH bulb, or light redirected through a light guide, for example), it can be difficult to produce sufficient intensities of desired wavelengths across the full footprint of the light emitted by the device. In other words, there are often "hot" and "cold" areas within the footprint of light generated concerning any given wavelength (6).

Besides that, multi-wave LCUs will have different curing modes (standard with $\approx 1000 \mathrm{~mW} / \mathrm{cm}^{2}$ or extra-power with $\approx 3200 \mathrm{~mW} / \mathrm{cm}^{2}$ ) with higher irradiance to be used with shorter exposure time, but the light distribution might remain uneven. Given that, the use of higher irradiance and short exposure time associated with an uneven distribution of the LCU spectral output might lead to different curing profiles towards the $\mathrm{RBC}$ restoration $(6,10)$.

Thus, the aim of this study was to evaluate the spectral output and beam profile of a multi-wave LCU, and its influence on the light transmittance, depth of cure, and curing profile of a bulk fill composite using different light-curing modes. The hypotheses tested were that: $\mathrm{H} 1$ - The multi-wave LCU would have different spectral output and beam profile distribution accordingly to each light-curing mode; $\mathrm{H} 2$ - The differences in spectral output and beam profile distribution for each light-curing mode would affect the light transmittance, depth of cure and degree of conversion in-depth (or curing profile) of a bulk fill composite.

\section{Material and Methods}

\section{Characterization of the Light Curing Unit}

The mean irradiance $\left(\mathrm{mW} / \mathrm{cm}^{2}\right)$ of the multi-wave LED light-curing unit (VALO ${ }^{\mathrm{Tm}}$ Cordless, Ultradent, South Jordan, UT, USA) was measured using a spectrophotometer coupled to an integrated sphere (MARC Light Collector, BlueLight Analytics, Nova Scotia, Canada) to calculate the photoactivation time needed to produce a radiant exposure of $20 \mathrm{~J} / \mathrm{cm}^{2}$ using two light-curing modes: Standard mode $\left(\approx 1000 \mathrm{~mW} / \mathrm{cm}^{2}\right.$, according to the manufacturer) or Xtra-Power mode $\left(\approx 3200 \mathrm{~mW} / \mathrm{cm}^{2}\right.$, according to the manufacturer). The radiant exposure in the violet range $(380-420 \mathrm{~nm})$, blue range $(420-495 \mathrm{~nm})$, and overall range $(380-495 \mathrm{~nm})$ was obtained by integrating the irradiance versus wavelength obtained with the same spectrophotometer.
The beam profile of each multi-wave LED mode was characterized using a Light Beam Profiler. The multi-wave LED was attached to an $x-y-z$ positioning device mounted on an optical bench to standardize the positioning of the light beam in contact with the diffusive surface of the frosted quartz target (DG20-1500, Thor Laboratories, Newton, NJ), while the resulting image was recorded using a digital CMOS detector (ASI174MM, ZWO ASI, Suzhou, China) with the optical analysis software (Fiji, ImageJ, National Institute of Health, Bethesda, MD, USA). The software was calibrated according to the pixel scale of the camera and the pixel dimensions to enable precise linear measurement of each curing light irradiance, and then the irradiance was multiplied by the exposure time of each light-curing mode (Standard or Xtra-Power) resulting in a color-coded scale in radiant exposure $\left(\mathrm{J} / \mathrm{cm}^{2}\right)$ unit of measurement. Lastly, narrow bandpass filters (Thor Labs Inc., Newton, NJ, USA) were used to differentiate the spectral output in the 380-420 nm (FB400-40 - peak at $400 \mathrm{~nm}$ and FWHM 40), 435-445 nm (FB440-10 - peak at $440 \mathrm{~nm}$ FWHM 10) and 455-465 nm (FB460-10 - peak at $460 \mathrm{~nm}$ FWHM 10) wavelength ranges and to identify the LED chips with a spectrum emission peak at $405 \mathrm{~nm}, 440$ $\mathrm{nm}$ and $460 \mathrm{~nm}$ of the multi-wave LED.

\section{Light Transmittance Analysis}

Table 1 lists the composition and characteristics of the bulk fill composite evaluated, Tetric EvoCeram ${ }^{\circledast}$ bulk fill. Light transmittance through the bulk fill composite was recorded during curing using the multi-wave LED in each light-curing mode evaluated (Standard or XtraPower mode). Non-polymerized increments of the bulk fill composite with different thicknesses $(1 \mathrm{~mm}, 2 \mathrm{~mm}, 3 \mathrm{~mm}$ and $4 \mathrm{~mm})(\mathrm{n}=3)$ were placed in Delrin molds placed on the bottom sensor $(\emptyset=4 \mathrm{~mm})$ of the MARC ${ }^{\otimes}$ Light Collector with Mylar strips covering the top and bottom surfaces. The spectral radiant power and the radiant exposure transmitted through the bulk fill composite on the bottom surface were calculated by integrating the irradiance over the different wavelength ranges from the graph of irradiance versus wavelength obtained with the spectrometer.

\section{Depth of Cure Analysis}

The depth of cure of the bulk fill composite was

Table 1. Manufacturer, photoinitiator system and composition of each bulkfill composite evaluated

\begin{tabular}{lccccc}
\hline $\begin{array}{l}\text { Bulkfill composite } \\
\text { (Shade/LOT) }\end{array}$ & Manufacturer & Photoinitiator system & Resin composition & Filler amount (wt\%/vol\%) & Depth of cure§ \\
\hline $\begin{array}{l}\text { Tetric EvoCeram Bulkfill } \\
\text { (IVW/P832346) }\end{array}$ & $\begin{array}{c}\text { Ivoclar Vivadent, } \\
\text { Schaan, Lietchtenstein }\end{array}$ & $\begin{array}{c}\text { CQ, EDMAB, TP0, } \\
\text { Ivocerin }\end{array}$ & $\begin{array}{c}\text { BisGMA, BisEMA, } \\
\text { UDMA }\end{array}$ & $\begin{array}{c}\text { Barium glass, YbF3, oxide, } \\
\text { PPF (81/61) }\end{array}$ \\
\hline
\end{tabular}

*Camphorquinone (CQ), diphenyl(2,4,6-trimethylbenzoyl)phosphine oxide (TP0), Bisphenol A glycidyl methacrylate (BisGMA), Ethoxylated bisphenol A methacrylate (BisEMA), Urethane dimethacrylate (UDMA), Poly(oxy-1,2-ethanediyl) (EPO), Triethylene glycol dimethacrylate (TEGDMA), Ytterbium trifluoride (YbF3), prepolymerized fillers (PPF). § According to the manufacture 
performed according to ISO 4049 (11). The bulk fill composite was placed in bulk in a cylindrical metal mold (12 $\mathrm{mm}$ in height, the internal diameter of $4 \mathrm{~mm}$ ). The topside of the mold was covered with a Mylar strip and pressed with a glass plate to obtain a flat surface. Light-curing was performed using the multi-wave LED in the Standard mode and Xtra-Power mode with $20 \mathrm{~J} / \mathrm{cm}^{2}$. After curing and removal from the mold, the bulk fill composite cylinder was placed into a hermetically sealed capsule containing 99.9 percent acetone (Sigma Aldrich, St. Louis, MO, USA). The capsule was vibrated on a mixing device for $15 \mathrm{~s}$ to remove the uncured material. The bulk fill composite specimen was removed from the container and dried. The height of the specimens was measured (in $\mathrm{mm}$ ) using a digital caliper (Mitutoyo, Miyazaki, Japan) and divided by two, as defined for the depth of cure test in ISO 4049. ${ }^{14}$

\section{Degree of Conversion In-Depth Analysis}

The specimens used for the depth of cure test were also used to map the degree of conversion throughout the bulk fill composite. Cross-section specimens ( $4 \mathrm{~mm} \times 6 \mathrm{~mm} \times 0.5$ $\mathrm{mm}$ thick) from the center, perpendicular to the top surface and parallel to the long axis of the cylindrical specimens were obtained using an automated water-cooled low-speed diamond saw (Isomet 1000, Buehler Ltd., Lake Bluff, IL, USA). The specimens were fixed onto a glass slab and placed over an automated $x-y$ axis microscope platform. The degree of conversion (DC) was mapped along the cross-section (width: $4 \mathrm{~mm}$, depth: $6 \mathrm{~mm}$ ) using an FT-NIR Microscope (Nicolet Continuum, Thermo Scientific, Waltham, MA, USA) coupled to an FT-NIR spectrometer (Nicolet Nexus 6700, Thermo Scientific, Waltham, MA, USA). Every $500 \mu \mathrm{m}$ in width and depth, an infrared spectrum was collected, resulting in 168 measuring points for each cross-section. The measurements started from $300 \mu \mathrm{m}$ below the top surface to avoid the area of oxygen inhibition. At each measurement position, the specimens NIR spectrums were collected in transmission mode with 50 scans of $4 \mathrm{~cm}^{-1}$ of resolution and a detector aperture size of 50 . Spectra of uncured specimens $(n=3)$ obtained with the same settings were used as a reference to measure the peak area ratio corresponding to the aromatic and vinyl stretching absorptions. The DC (in \%) was calculated as follows:

$$
\mathrm{DC}=\left[1-\left(\frac{\text { vinyl peak area/aromatic peak area pol }}{\text { vinyl peak area/aromatic peak area non pol }}\right)\right] \times 100
$$

where pol and non-pol correspond to the area of the methacrylate peak for the polymeric and monomeric states, respectively.

The results were exported into mapping software
(OriginPro 2015, OriginLab Co., Northampton, MA, USA). Color-coded maps were created with a linear smoothing parameter of 1 to describe the DC as a function of the position under the light beam in width (0 to $4 \mathrm{~mm}$ ) and in-depth $(0$ to $6 \mathrm{~mm}$ ). Also, the map scales were set to indicate the maximum DC achieved with the bulk fill composite and a reduction of 10\% of the maximum DC in each color-coded area.

\section{Statistical Analysis}

All data were submitted to the Shapiro-Wilk test to check the normality. For the depth of cure, the t-Student test was performed $(\alpha=0.05)$. For the radiant exposure transmitted in each wavelength spectrum range (380$420 \mathrm{~nm}$ or $420-495 \mathrm{~nm}$ ) analysis of covariance (ANCOVA) was performed where the light-curing modes (Standard or Xtra-Power) were the groups between subject and the thicknesses of the bulk fill composite $(1 \mathrm{~mm}, 2 \mathrm{~mm}, 3 \mathrm{~mm}$ and $4 \mathrm{~mm}$ ) were the co-variables. For the mapping of the degree of conversion, a split-plot analysis of variance (ANOVA) was used for the statistical analysis of the DC values. The independent variables were set as between subject groups for the light-curing mode (Standard or Xtra-Power) and within-subject groups for width $(0 \mathrm{~mm}$, $0.5 \mathrm{~mm}, 1 \mathrm{~mm}, 1.5 \mathrm{~mm}, 2 \mathrm{~mm}, 2.5 \mathrm{~mm}, 3 \mathrm{~mm}, 3.5 \mathrm{~mm}, 4$ $\mathrm{mm})$ and depths $(0 \mathrm{~mm}, 0.5 \mathrm{~mm}, 1 \mathrm{~mm}, 1.5 \mathrm{~mm}, 2 \mathrm{~mm}$, $2.5 \mathrm{~mm}, 3 \mathrm{~mm}, 3.5 \mathrm{~mm}, 4 \mathrm{~mm}, 4.5 \mathrm{~mm}, 5 \mathrm{~mm}, 5.5 \mathrm{~mm}$ and $6 \mathrm{~mm}$ ). The contrast analysis was performed for the determination of confidence intervals $(\mathrm{Cl})$ of the maximum dependent variable mean (maximum DC mean achieved on the top of the restoration) ( $\alpha=0.05)$, and the statistical results were plotted in a color-coded map accordingly to the $p$-values. Power analysis was conducted to determine the sample size for each experiment to provide a power test of at least 0.8 at a significance level of $0.05(\beta=0.2)$.

\section{Results}

\section{Characterization of the Light Curing Unit}

Table 2 shows mean irradiance and the total radiant exposure within each wavelength range (380-420 nm and 420-495 nm) for each light-curing mode used in this study. The multi-wave LED has a mean irradiance of $955 \mathrm{~mW} / \mathrm{cm}^{2}$ and $2244 \mathrm{~mW} / \mathrm{cm}^{2}$ in Standard and Xtra-Power light-curing mode, respectively. To achieve $20 \mathrm{~J} / \mathrm{cm}^{2}$ of radiant exposure, the exposure time was $21 \mathrm{~s}$ for the Standard mode and $9 \mathrm{~s}$ for Xtra-Power mode. Both light-curing modes emit approximately the same amount of radiant exposure in both wavelength range (violet, 380-420 nm, and blue, 420-495 $\mathrm{nm}$ ), despite the radiant exposure inside the blue range is approximately 3 times greater than violet range.

Figure 1 illustrates the beam profile of the Standard and Xtra-Power modes of the multi-wave LEDs tested. The 
multi-wave LED had an active area of emission of $0.723 \mathrm{~cm}^{2}$ and maximum radiant exposure of $2 \mathrm{~J} / \mathrm{cm}^{2}$. Still, the radiant exposure and the spectral output were not uniformly distributed across the tip for both light-curing modes. For the wavelength emission between $380-420 \mathrm{~nm}$, areas of higher radiant exposure were localized near to the violet LED chip at approximately $3 \mathrm{~mm}$ width and $3 \mathrm{~mm}$ height of the beam emission. On the opposite side, there is an area of higher radiant exposure in the wavelength emission between 455-465 nm localized near to the blue LED chip at approximately $7 \mathrm{~mm}$ width and $3 \mathrm{~mm}$ height of the beam emission. The third area of wavelength emission between 435-445 nm emission is localized at approximately $5 \mathrm{~mm}$ width and $8 \mathrm{~mm}$ height of the beam emission.

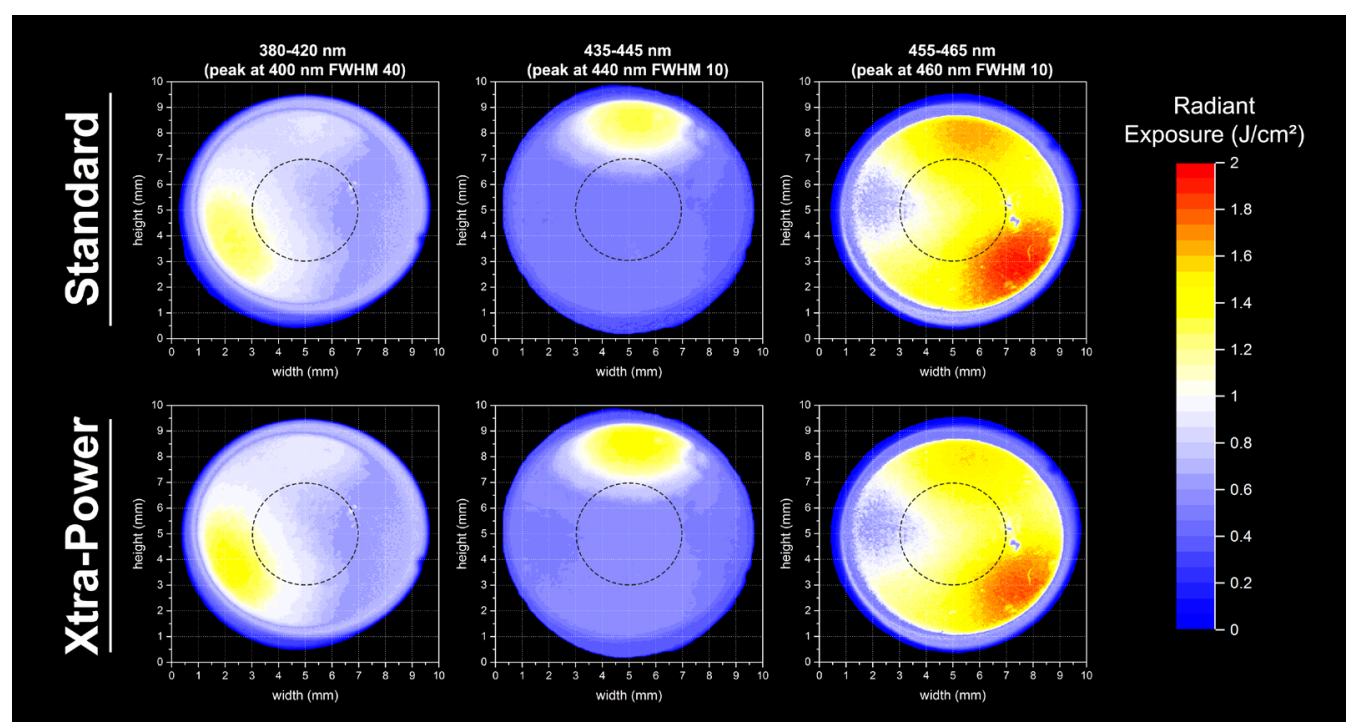

Figure 1. Graph representing the radiant exposure $(\mathrm{J} / \mathrm{cm} 2)$ versus the wavelength $(\mathrm{nm})$ of the multi-wave LCU (VALO ${ }^{\mathrm{TM}}$ Cordless) with cumulative energy of $20 \mathrm{~J} / \mathrm{cm} 2$ of radiant exposure using different curing modes (Standard - 955 $\mathrm{mW} / \mathrm{cm} 2$ for $21 \mathrm{~s}$; and Xtra-Power $-2244 \mathrm{~mW} / \mathrm{cm} 2$ for $9 \mathrm{~s}$ ). The different images in the columns show different bandpass filters narrowing the spectral emission pattern within the violet ( $380-420 \mathrm{~nm})$, royal blue $(435-445 \mathrm{~nm})$, and blue wavelength range (455 - $465 \mathrm{~nm}$ ). The black dashed circle area (- - -) represents the position, orientation, and area of the specimen onto the multi-wave LCU tip
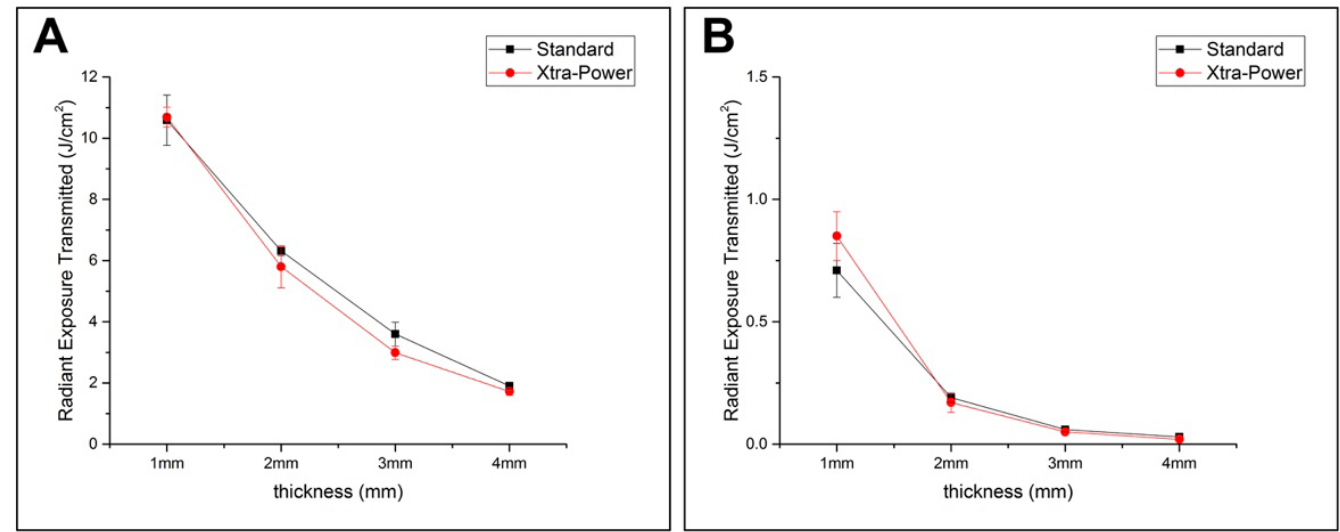

Figure 2. Radiant exposure transmitted $(\mathrm{J} / \mathrm{cm} 2)$ versus bulk fill composite thickness $(\mathrm{mm})$ of each light-curing mode for the (A) blue (420-495 $\mathrm{nm}$ ) and (B) violet (380-420 nm) wavelength ranges

Table 2. VALO Cordless LCU: mean $\left.{ }_{ \pm} \mathrm{SD}\right)$ radiant emittance $(\mathrm{mW} / \mathrm{cm} 2)$, exposure time and radiant exposure $\left(\mathrm{J} / \mathrm{cm}^{2}\right)$

\begin{tabular}{|c|c|c|c|c|c|c|c|}
\hline Mode & $\begin{array}{l}\text { Irradiance } \\
\left(\mathrm{mW} / \mathrm{cm}^{2}\right)\end{array}$ & $\begin{array}{l}\text { Violet Irradiance } \\
\left(\mathrm{mW} / \mathrm{cm}^{2}\right)\end{array}$ & $\begin{array}{l}\text { Blue Irradiance } \\
\left(\mathrm{mW} / \mathrm{cm}^{2}\right)\end{array}$ & $\begin{array}{l}\text { Exposure } \\
\text { time (s) }\end{array}$ & $\begin{array}{c}\text { Radiant } \\
\text { exposure }\left(\mathrm{J} / \mathrm{cm}^{2}\right)\end{array}$ & $\begin{array}{l}\text { Violet Radiant } \\
\text { exposure }\left(\mathrm{J} / \mathrm{cm}^{2}\right)\end{array}$ & $\begin{array}{l}\text { Blue Radiant } \\
\text { exposure }\left(\mathrm{J} / \mathrm{cm}^{2}\right)\end{array}$ \\
\hline Standard & $955( \pm 2)$ & $214( \pm 4)$ & $741( \pm 8)$ & 21 & 20 & $4.5( \pm 0.1)$ & $15.5( \pm 0.1)$ \\
\hline Xtra Power & $2244( \pm 10)$ & $555( \pm 7)$ & $1689( \pm 6)$ & 9 & 20 & $5( \pm 0.1)$ & $15( \pm 0.2)$ \\
\hline
\end{tabular}


Figure 2 illustrates the radiant exposure transmitted $\left(\mathrm{J} / \mathrm{cm}^{2}\right)$ versus bulk fill composite thickness $(\mathrm{mm})$ of each light-curing mode for the violet $(380-420 \mathrm{~nm})$ and blue (420-495 nm) wavelength ranges. The ANCOVA showed no statistical differences between Standard and Xtra-Power light-curing modes for violet and blue wavelength ranges. However, blue radiant exposure transmitted through the bulk fill composite was higher than violet radiant exposure.

\section{Depth of Cure Analysis}

There was no statistical difference in the depth of cure using Standard, $3.6 \mathrm{~mm}( \pm 0.3 \mathrm{~mm})$, or Xtra-Power lightcuring, $3.62 \mathrm{~mm}( \pm 0.2 \mathrm{~mm})$, modes $(p=0.42)$. However, both presented a lower depth of cure than the claimed by the manufacturer (4 mm).

\section{Degree of Conversion In-Depth Analysis}

Figure 3 shows the map of the DC (or curing profile) of the bulk fill composite and the $p$-value mapping of the contrast test according to the different light-curing modes. The maximum DC achieved by the bulk fill composite was approximately $64 \%$ on the top of the restoration for both light-curing modes. Comparing point by point at the same width and depth throughout the sample, Standard and XtraPower light-curing modes showed no statistical difference in the DC up to $4 \mathrm{~mm}$ in depth ( $>>0.05$ ).

\section{Discussion}

Radiant exposure $\left(\mathrm{J} / \mathrm{cm}^{2}\right)$ is considered as the main factor in determining light-cured resin-based materials properties, and the "exposure reciprocity law" states that similar properties can be achieved as long as radiant exposure is kept constant (12). This statement encourages dentists and manufacturers to use or suggest a shorter exposure time at higher irradiance. However, stating a single radiant exposure value cannot adequately describe or correlate with the light output spectra from a multi- wave LCU.

Despite the same radiant exposure $\left(20 \mathrm{~J} / \mathrm{cm}^{2}\right)$ for both light-curing modes tested (Standard and Xtra-Power modes), the blue radiant exposure was higher than violet radiant exposure for both modes (Fig. 1). The VALO ${ }^{\text {TM }}$ Cordless is a multi-wave LED with three different emission peaks wherein the first LED light source comprises two LEDs with a peak emission within $460 \mathrm{~nm}$ (royal blue), the second LED light source comprises a LED with a peak emission within $440 \mathrm{~nm}$ (cyan blue) and the third LED light source comprises LED with a peak emission within $405 \mathrm{~nm}$ (violet); thus some of the spectral power is emitted in the violet wavelength region $\left(4.5 \mathrm{~J} / \mathrm{cm}^{2}\right)$, but the majority is emitted in the blue wavelength region $\left(15.5 \mathrm{~J} / \mathrm{cm}^{2}\right)$, as shown in Table 2. Other studies also demonstrated a higher radiant exposure of multi-wave LEDs into the blue wavelength range in comparison to the violet $(6,9)$.

Previous studies described the light outputs from different LCUs in the different exposure modes showing that for the multi-wave LED unit used in this study, the spectral emission within the violet range is increased when the overall radiant power output is increased $(12,13)$. Given the preceding, there exists a need to develop dental curing lights including multiple LEDs capable of providing more even intensities of any given wavelength across the full footprint of the light emitted. The VALO ${ }^{\text {TM }}$ Cordless (Ultradent, South Jordan, UT, USA) is a widely used LCU, and it is showing one of the most reliable in terms of photoactivation of different resin-based materials regardless the photoinitiator system.

As previously described, the VALO ${ }^{\text {TM }}$ Cordless has four LED chips, one that emits violet light with spectral peak at $405 \mathrm{~nm}$, and the other three that emit blue light, with one chip with spectral peak at $440 \mathrm{~nm}$, and the other two with spectral peak at $460 \mathrm{~nm}$. Besides that, the VALO ${ }^{\text {TM }}$ Cordless uses a diffusive quartz glass lens (also known as microlens) to mix the different light wavelengths output across the emitted beam. The collimation of the light beam by the microlens maintains the intensity across $10 \mathrm{~mm}$ diameter
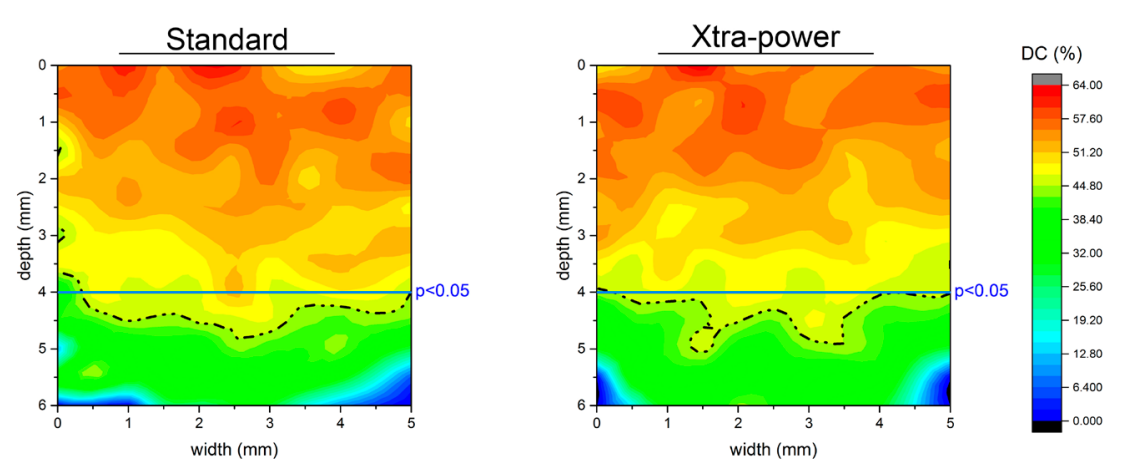

Figure 3. Degree of conversion map (DC, in \%) of the bulk fill composite according to the different light-curing modes, Standard or Xtra-Power, and LED chips distribution, violet (380-420 $\mathrm{nm}$ from 0 to $2 \mathrm{~mm}$ in width) and blue (420-495 $\mathrm{nm}$ from 3 to $5 \mathrm{~mm}$ in width). The black dashed line (- - - -) in the graphs represents the limit boundary of $80 \%$ of the maximum DC achieved by the bulk fill composite. light tip from the VALO ${ }^{\text {TM }}$ Cordless. However, the irradiance within different wavelengths was not be uniformly distributed across the tip. Thus, the first research hypothesis that the multiwave LCU would have different spectral output and beam profile distribution accordingly to each light-curing mode was accepted.

However, contrary to expectation, the second research hypothesis that the differences in spectral output and beam profile 
distribution for each light-curing mode would affect the light transmittance, depth of cure and degree of conversion in-depth (or curing profile) of bulk fill composites was rejected.

Photoinitiator absorption and curing light peak emission, as well as the curing light irradiance $\left(\mathrm{mW} / \mathrm{cm}^{2}\right)$ and exposure time (s) are considered as main factors to ensure adequate light curing of RBCs (14). According to the manufacturer, the minimum time of exposure recommended to light-cure the bulk fill composite tested is $20 \mathrm{~s}$ at about $1000 \mathrm{~mW} /$ $\mathrm{cm}^{2}$ with a multi-wave LED. This corresponds to a $20 \mathrm{~J} / \mathrm{cm}^{2}$ of radiant exposure. However, there are many intrinsic and extrinsic factors that could affect the DC and the depth of cure of resin-based materials $(5,15,16)$. Intrinsic factors are related with photoinitiator type and its concentration, as well as, viscosity (co-monomer composition and ratio, filler content) and optical properties $(5,14,17)$.

The bulk fill composite tested contains CQ-amine, TPO, and Ivocerin as photoinitiator systems. The multiwave LED tested has three peak emission (405 nm, 440 $\mathrm{nm}$, and $460 \mathrm{~nm}$ ) that fits into the absorption spectrum of all these three types of photoinitiators (TPO $<405 \mathrm{~nm}$, Ivocerin $\sim 418 \mathrm{~nm}$ and CQ $468 \mathrm{~nm}$ ). Although TPO and Ivocerin have a higher molar extinction coefficient and requires lower radiant exposure than $\mathrm{CO}$-amine system (18), the violet radiant exposure that excite these photoinitiators is lower than the blue radiant exposure. Moreover, the violet light is not transmitted in depth throughout the entire bulk fill composite. As showed in Figure $2 \mathrm{~B}$, the radiant exposure of violet light transmitted to the bottom of the bulk fill composite was practically null. This phenomenon is very likely to happen because the violet light is the shortest wavelength from the visible spectrum. Due to the differences in the refractive indexes of the different components of RBC formulations (fillers, monomers, pigments, etc.), light scattering is expected, attenuating light transmittance through the material (10). As a consequence, more attenuation is expected for shorter wavelengths, such as the violet light, than for longer wavelength, such as the blue light, for example.

Thus, the use of alternative photoinitiator systems that absorb in shorter wavelength ranges, such as violet light, might not improve the depth of cure of bulk fill composites. Other studies also demonstrated the lower depth of cure of Norrish type I (TPO or Ivocerin) materials in comparison to CQ $(10,19)$. However, it worthwhile to point out that other physical properties can be improved when TPO is combined with $\mathrm{CO}$, such as color change during curing and color stability $(10,20-22)$.

The depth of cure results using the ISO 4049:2019 method (Fig. 3) corroborates that Tetric EvoCeram ${ }^{\circledast}$ bulk fill had a depth of cure lower than $4 \mathrm{~mm}(23,24)$. However, this method might underestimate the depth of cure of bulk fill composites (25), and the use of other methods such as DC measurement in depth can be more precise to determinate the curing profile of bulk fill composites in depth (6). As demonstrated in these previous studies $(6,23-25)$, the correlation among different tests used to determine the depth of cure can provide completely different results. The optical and scraping methods correlate well, but both overestimate the depth of cure when compared with acceptable hardness and degree of conversion values. Although Knoop Hardness correlate well with degree of conversion, the degree of conversion drastically reduces as depth increases. Therefore, the degree of conversion seems to be the most sensitive test to evaluate the depth of cur, especially for bulk fill composites.

Moreover, it is commonly considered that if the surface microhardness is at least $80 \%$ of the maximum hardness, then the RBC has an adequate hardness value. However, the use of such analysis is very weak, and these threshold numbers are driven only by convenience. In this paper, the statistical analysis consisted of a split-plot ANOVA, which is considered more reliable when inferring evidence-based conclusions to a research question. As observed in Figure 4, no statistical differences were found in the DC up to $4 \mathrm{~mm}$ in depth, despite the lower depth of cure found when ISO 4049 (Fig. 3) or the $80 \%$ bottom/top ratio that were taken in consideration. The question that remains unanswered is if it is safe to only rely on the ISO 4049. As exemplified in this study, bulk fill composites have the potential to deliver more promising in-vitro results than is being reported and claimed so far, since the test methods used to regulate these materials are not accurate.

Regarding the reciprocity law, this study found that there was no statistical difference despite the curing mode. Even though Norrish type I photoinitiators, such as TPO and Ivocerin, can absorb and react more efficiently when activated with higher irradiances, their combination with $\mathrm{CO}$ seems to ensure efficiency regardless the curing mode. All these assertions seem to be a trend in the dental material industry, considering that manufacturers such as Ivoclar Vivadent have recently launched a power cure system with resin-based materials that can be cured in $3 \mathrm{~s}$. Even if exposure reciprocity law holds for some materials, it does not work for others $(14,17)$. Further studies should investigate the importance of LCU spectral output and photoinitiator system with different absorption profiles on the curing profile of bulk fill composites cured using different curing modes.

Thus, within the limitations of this study, it was possible to conclude that the reduction in exposure time using the same radiant exposure did not affect the light transmittance, depth of cure or degree of conversion in 
depth of the bulk fill composite formulation.

\section{Resumo}

0 objetivo deste estudo foi avaliar o efeito da lei de reciprocidade de um diodo emissor de luz (LED) multi-wave na transmitância de luz (LT), profundidade de cura (DOC) e grau de conversão em profundidade (DC) de um compósito bulk fill. Material e Métodos: Um compósito bulk fill (EvoCeram ${ }^{\circledR}$, Ivoclar Vivadent) foi fotoativado utilizando um LED multiwave (VALO ${ }^{\mathrm{TM}}$ Cordless, Ultradent). 0 LED foi previamente caracterizado usando um espectrofotômetro para padronizar o tempo de exposição utilizando os modos Standard ou Xtra-Power com a mesma dose de energia de $20 \mathrm{~J} / \mathrm{cm}^{2}$. A LT foi avaliada através de amostras do compósito bulk fill a cada milimetro até $4 \mathrm{~mm}$ de profundidade. 0 DOC foi avaliado de acordo com a ISO 4049. O DC foi realizado em forma de mapeamento da seção transversal longitudinal central de cada amostra do teste de DOC utilizando microscopia FT-NIR. Os dados foram analisados estatisticamente de acordo com o delineamento experimental $(\alpha=0,05 ; \beta=0,2)$. A exposição radiante na faixa de comprimento de onda violeta para os modos $S t a n d a r d$ e Xtra-Power foi de 4,5 e $5,0 \mathrm{~J} / \mathrm{cm}^{2}$, respectivamente; e para a faixa de comprimento de onda azul, a exposição radiante para os modos Standard e Xtra-Power foi de 15,5 e $15,0 \mathrm{~J} / \mathrm{cm}^{2}$, respectivamente. Não houve diferença estatística no DOC utilizando os modos de fotopolimerização Standard ou Xtra-Power, mas o DOC foi menor do que o reivindicado pelo fabricante (4 mm). 0 DC não foi afetado significativamente pelo modo de fotopolimerização até $4 \mathrm{~mm}$ de profundidade $(p>0,05)$. De acordo com a lei de reciprocidade da exposição, a redução no tempo de exposição utilizando a mesma exposição radiante não afetou a profundidade de cura do compósito bulk fill.

\section{Acknowledgements}

The authors acknowledge that this study was partially supported by Fundação de Amparo a Pesquisa do Estado de São Paulo (FAPESP) (grants \#2016/06019-3, \#2017/22195-9, \#2016/05823-3 and \#2017/22161-7).

\section{References}

1. Randolph LD, Palin WM, Bebelman S, Devaux J, Gallez B, Leloup G, et al. Ultra-fast light-curing resin composite with increased conversion and reduced monomer elution. Dent Mater 2014;30:594-604.

2. Randolph LD, Palin WM, Watts DC, Genet M, Devaux J, Leloup G, et al. The effect of ultra-fast photopolymerisation of experimental composites on shrinkage stress, network formation and pulpal temperature rise. Dent Mater 2014;30:1280-1289.

3. Lima AF, Formaggio SE, Zambelli LF, Palialol AR, Marchi GM, Saraceni

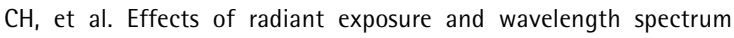
of light-curing units on chemical and physical properties of resin cements. Restor Dent Endod 2016;41:271-277.

4. Platt JA, Price RB. Light curing explored in Halifax. Oper Dent 2014;39:561-563.

5. Leprince JG, Hadis M, Shortall AC, Ferracane JL, Devaux J, Leloup G, et al. Photoinitiator type and applicability of exposure reciprocity law in filled and unfilled photoactive resins. Dent Mater 2011;27:157-164.

6. Rocha MG, de Oliveira D, Correa IC, Correr-Sobrinho L, Sinhoreti M, Ferracane JL, et al. Light-emitting Diode Beam Profile and Spectral Output Influence on the Degree of Conversion of Bulk Fill Composites. Oper Dent 2017;42:418-427.

7. Neumann MG, Miranda WG, Jr., Schmitt CC, Rueggeberg FA, Correa IC. Molar extinction coefficients and the photon absorption efficiency of dental photoinitiators and light curing units. J Dent 2005;33:525-532.

8. Neumann MG, Schmitt CC, Ferreira GC, Correa IC. The initiating radical yields and the efficiency of polymerization for various dental photoinitiators excited by different light curing units. Dent Mater 2006;22:576-584

9. de Oliveira DC, Rocha MG, Gatti A, Correr AB, Ferracane JL, Sinhoreti MA. Effect of different photoinitiators and reducing agents on cure efficiency and color stability of resin-based composites using different LED wavelengths. J Dent 2015;43:1565-1572.

10. de Oliveira DC, Rocha MG, Correa IC, Correr AB, Ferracane JL, Sinhoreti MA. The effect of combining photoinitiator systems on the color and curing profile of resin-based composites. Dent Mater 2016;32:12091217.

11. International Organization for Standardization. ISO 4049:2000. Dentistry - Polymer-based filling restorative and luting materials, 2000.

12. Feng L, Suh BI. Exposure reciprocity law in photopolymerization of multi-functional acrylates and methacrylates. Macromol Chem Phys 2007:208:295-306

13. Harlow JE, Sullivan B, Shortall AC, Labrie D, Price RB. Characterizing the output settings of dental curing lights. J Dent 2016;44:20-26.

14. Rueggeberg FA. State-of-the-art: dental photocuring - a review. Dent Mater 2011;27:39-52.

15. Price RB, Felix $\mathrm{CM}$, Whalen JM. Factors affecting the energy delivered to simulated class I and class $v$ preparations. J Can Dent Assoc 2010;76:a94.

16. Price RB, Derand $T$, Sedarous $M$, Andreou $P$, Loney RW. Effect of distance on the power density from two light guides. J Esthet Dent 2000;12:320-327.

17. Beun S, Bailly C, Dabin A, Vreven J, Devaux J, Leloup G. Rheological properties of experimental Bis-GMA/TEGDMA flowable resin composites with various macrofiller/microfiller ratio. Dent Mater 2009;25:198-205.

18. Moszner N, Fischer UK, Ganster B, Liska R, Rheinberger V. Benzoyl germanium derivatives as novel visible light photoinitiators for dental materials. Dent Mater 2008;24:901-907.

19. Delgado AJ, Castellanos EM, Sinhoreti MAC, Oliveira DC, Abdulhameed, Geraldeli $S$, et al. The use of different photoinitiator systems in photopolymerization resin cements through ceramic veneers. Oper Dent 2019;44:396-404

20. Salgado VE, Borba MM, Cavalcante LM, Moraes RR, Schneider LF. Effect of photoinitiator combinations on hardness, depth of cure, and color of model resin composites. J Esthet Restor Dent. 2015;27:S41-48.

21. Hadis MA, Shortall AC, Palin WM. Competitive light absorbers in photoactive dental resin-based materials. Dent Mater 2012;28:831841.

22. Castellanos M, Delgado AJ, Sinhoreti MAC, Oliveira DCRS, Abdulhameed $\mathrm{N}$, Geraldeli $\mathrm{S}$, et al. Effect of thickness of ceramic veneers on color stability and bond strength of resin luting cements containing alternative photoinitiators. J Adhes Dent 2019;21:67-76.

23. AIQahtani MQ, Michaud PL, Sullivan B, Labrie D, AIShaafi MM, Price RB. Effect of High Irradiance on Depth of Cure of a Conventional and a Bulk Fill Resin-based Composite. Oper Dent 2015;40:662-72.

24. Benetti AR, Havndrup-Pedersen $C$, Honore D, Pedersen MK, Pallesen U. Bulk-fill resin composites: polymerization contraction, depth of cure, and gap formation. Oper Dent 2015;40:190-200.

25. Price RB, Rueggeberg FA, Harlow J, Sullivan B. Effect of mold type, diameter, and uncured composite removal method on depth of cure. Clin Oral Investig 2016;20:1699-1707.
Received July 15, 2020

Accepted November 30, 2020 